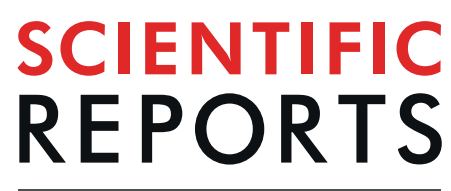

natureresearch

\title{
Place of death trends among patients with dementia in Japan: a population-based observational study
}

\author{
Toshihiro Koyama $\mathbb{1}^{1 *}{ }^{*}$, Misato Sasaki ${ }^{1}$, Hideharu Hagiya ${ }^{2}$, Yoshito Zamami $\mathbb{D}^{3}$, \\ Tomoko Funahashi ${ }^{4}$, Ayako Ohshima ${ }^{1}$, Yasuhisa Tatebe ${ }^{5}$, Naoko Mikami ${ }^{6}$, \\ Kazuaki Shinomiya ${ }^{7}$, Yoshihisa Kitamura ${ }^{5}$, Toshiaki Sendo ${ }^{5}$, Shiro Hinotsu ${ }^{8}$ \& \\ Mitsunobu R. Kano $\mathbb{1}^{4,9}$
}

Dementia is a major public health concern in ageing societies. Although the population of Japan is among the most aged worldwide, long-term trends in the place of death (PoD) among patients with dementia is unknown. In this Japanese nationwide observational study, we analysed trends in PoD using the data of patients with dementia who were aged $\geq 65$ years and died during 1999-2016. Trends in the crude death rates and PoD frequencies were analysed using the Joinpoint regression model. Changes in these trends were assessed using the Joinpoint regression analysis in which significant change points, the annual percentage change (APC) and average APCs (AAPC) in hospitals, homes, or nursing homes were estimated. During 1999-2016, the number of deaths among patients with dementia increased from 3,235 to 23,757 (total: 182,000). A trend analysis revealed increased mortality rates, with an AAPC of $8.2 \%$ among men and $9.3 \%$ among women. Most patients with dementia died in the hospital, although the prevalence of hospital deaths decreased (AAPC: $-1.0 \%$ ). Moreover, the prevalence of nursing home deaths increased (AAPC: $5.6 \%$ ), whereas the prevalence of home deaths decreased (AAPC: $-5.8 \%$ ). These findings support a reconsideration of the end-of-life care provided to patients with dementia.

Dementia, a progressive disorder of brain function associated with memory deficits, changes in behaviour and personality and impaired reasoning, is mainly a consequence of Alzheimer's disease, cerebrovascular disease, and Lewy body disease. Patients with advanced dementia also tend to develop complications such as pneumonia, febrile episodes and eating problems during the final stages of life, which are associated with high mortality rates ${ }^{1}$. Although these complications are harbingers or direct causes of death, dementia is the major causative illness and is therefore the underlying cause of mortality reported on death certificates.

Dementia has become the leading cause of death among older people and is considered a major public health problem in the era of global ageing, given its incurable nature. The increasing rate of ageing worldwide has led

\footnotetext{
${ }^{1}$ Department of Pharmaceutical Biomedicine, Graduate School of Medicine, Dentistry, and Pharmaceutical Sciences, Okayama University, 1-1-1 Tsushima-Naka, Kita-ku, Okayama, 700-8530, Japan. ${ }^{2}$ Department of General Medicine, Graduate School of Medicine, Dentistry and Pharmaceutical Sciences, Okayama University, 2-5-1 Shikatacho, Kita-ku, Okayama, 700-8558, Japan. ${ }^{3}$ Department of Clinical Pharmacology and Therapeutics, Tokushima University Graduate School, 3-1815 Kuramoto, Tokushima, 770-8503, Japan. ${ }^{4}$ Department of Pharmaceutical Biomedicine, Graduate School of Interdisciplinary Science and Engineering in Health Systems, Okayama University, 1-1-1 Tsushima-naka, Kita-ku, Okayama, 700-8530, Japan. ${ }^{5}$ Department of Pharmacy, Okayama University Hospital, 2-5-1 Shikata-cho, Okayama, 700-8558, Japan. ${ }^{6}$ Division of Pharmacy, Chiba University Hospital, 1-8-1 Inohana, Chuo-ku, Chiba, 260-8677, Japan. ${ }^{7}$ Department of Pharmaceutical Care and Clinical Pharmacy, Faculty of Pharmaceutical Sciences, Tokushima Bunri University, 180 Nishihamabouji Yamashiro-cho, Tokushima, 770-8514, Japan. ${ }^{8}$ Department of Biostatistics, Sapporo Medical University, South 1, West 17, Chuo-ku, Sapporo, Hokkaido, 060-8556, Japan. ${ }^{9}$ Department of Geriatric Medicine, University of Tokyo, 7-3-1 Hongo, Bunkyo-ku, Tokyo, 1138655, Japan. *email: koyama-oka@umin.ac.jp
} 
to predictions that people aged $\geq 60$ years will comprise $35 \%$ of the European population and $28 \%$ of the North American population by $2050^{2}$. In Japan, estimates suggest that people aged $\geq 65$ years will comprise approximately $40 \%$ of the entire population by $2050^{3}$. Additional predictions suggest that between 2016 and 2050 , the number of people aged $\geq 60$ years will double in most middle-income countries, as well as in developed countries $^{2}$. The World Health Organisation suggests that ageing profoundly exacerbates the number of patients with dementia worldwide ${ }^{4}$. In Japan, the Ministry of Health, Labour and Welfare publishes estimates of the populations of patients by disease and age every 3 years. According to these statistics, the estimated prevalence of dementia among people aged $\geq 65$ years had increased from 681.9 per 100,000 people in 1999 to 2029.5 per 100,000 people in $2014^{5}$.

People who develop advanced dementia face a reduced survival duration, particularly due to an impaired swallowing function and complications associated with aspiration pneumonia. These issues raise concerns on the increased mortality associated with the disease ${ }^{1,6}$. Thus, as the number of patients with dementia has increased, end-of-life care has become a globally important subject ${ }^{7}$. One important indicator of the quality of end-of-life care involves whether patients can experience their last moment at a place of their choice ${ }^{8}$. In Japan, long-term care policies have changed over time to support the patient's preferences regarding their end-of-life care ${ }^{9}$. Therefore, a deep understanding of the places of death (PoDs) of patients with dementia can provide indispensable information for planning health care policies related to the provision of end-of-life care services and the long-term planning of medical and long-term care facilities. In the United States and European countries, several studies have reported mortality rates and prevalence of PoDs among patients with dementia ${ }^{10-14}$. To the best of our knowledge, however, these rates remain unknown in Japan, a country with one of the most aged populations. In this study, therefore, we aimed to investigate the trends in mortality rates and PoD among older people (aged $\geq 65$ years) with dementia in Japan by age and sex.

\section{Methods}

Data sources. This population-based observational study spanned an 18-year period in Japan. Data on the number of dementia-associated deaths by sex, age, and PoD were obtained from the Vital Statistics of Japan which were based on the death certificates collected by the Japanese Ministry of Health, Labour, and Welfare following the international coding rules of the World Health Organisation ${ }^{15}$. All death certificates are completed by a physician within 1 week after death, and the direct and underlying causes of death and PoDs are recorded and reported to the health ministry through regional health centres. Therefore, the Japanese death certificate database is a high-quality, nationally representative source of information. All deaths from 1999 to 2016 for which dementia was registered as an underlying cause of death were extracted using the International Classification of Diseases (ICD) $10^{\text {th }}$ revision ${ }^{16}$, including the codes G30 (Alzheimer's disease), F01 (vascular dementia), and F03 (unspecified dementia) according to the previous literature ${ }^{11-13}$. The data of people aged $\geq 65$ years were stratified by age and sex to determine crude mortality rates per 100,000 persons per year. To confirm the impacts of demographic changes, we calculated the age-standardised death rates per 100,000 persons to exclude the effects of demographic changes throughout the study period. Therefore, we used a direct-standardisation method based on the Japanese population structure in 1999 as a standard population and 5-year age groups (Supplementary Figure S1). The following age groups were categorised: $65-74,75-84$, and $\geq 85$ years. PoD was defined from the death certificate and classified as hospital (hospital or physician's office), nursing home (care home or nursing care home), or own home. The numbers of deaths by age group and place are provided in Supplementary Tables S1 and S2, respectively.

Statistical analysis. Mortality rates are presented as crude rates per 100,000 people in the entire population and each age subgroup. The proportions of PoDs are expressed as percentages and were determined by dividing the number of deaths at each hospital, nursing home, and home by the total number of deaths occurring during the year.

To estimate trends in the mortality rate and the proportions of PoDs, the Joinpoint regression model was applied using the Joinpoint Regression Programme, version 4.6.0.0 (National Cancer Institute) ${ }^{17}$. The annual percentage change (APC) between trend-change points, together with its confidence interval (CI), was determined using the Joinpoint regression analysis. A $p$-value $<0.05$ was defined as the significance level when the slope was statistically significantly different from zero. To compare differences in mortality trends among population subgroups, we estimated the average annual percentage change (AAPC) over the entire period. Data processing and aggregation were performed using Microsoft Access ${ }^{\circledR} 2013$ (Microsoft Corporation, Redmond, WA, USA).

Ethics approval. This study used data provided by the Japanese Ministry of Health, Labour, and Welfare and the Statistics Bureau of the Ministry of Internal Affairs and Communications. Because these data are fully anonymised and available to the public, the ethics committee of Okayama University Hospital deemed that there was no requirement for a formal ethical review. This study was an observational study based on anonymised information, with no treatment intervention and no collection of human samples. Therefore, the requirement to obtain informed consent was waived.

\section{Results}

Among older Japanese adults aged $\geq 65$ years with dementia, 182,077 deaths attributed to dementia were recorded in the death certificate database throughout the study period. The mortality rate increased from 15.3 per 100,000 people in 1999 to 69.0 per 100,000 people in 2016 (Fig. 1).

By age, the crude mortality rates per 100,000 adults with dementia aged $65-74,75-84$, and $\geq 85$ years increased from $2.4,14.9$, and 94.6 to $4.8,43.1$, and 344.5 , respectively, over the study period. The mortality rate among male adults aged $\geq 65$ years increased from 11.5 per 100,000 people in 1999 to 47.2 per 100,000 people in 


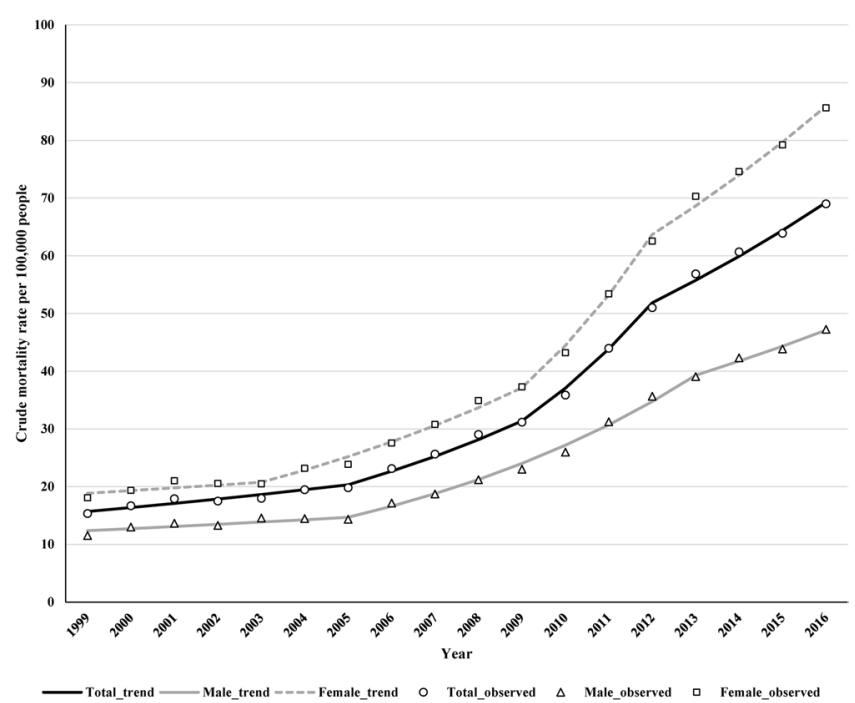

Figure 1. Trends in the crude mortality rates associated with dementia per 100,000 people aged $\geq 65$ years by sex during 1999-2016.

2016. The mortality rates among male adults aged $65-74,75-84$, and $\geq 85$ years increased from $2.5,15.8$, and 81.1 per 100,000 people in 1999 to 5.7, 47.0, and 269.9 per 100,000 people in 2016, respectively (Fig. 2). Among female adults aged $\geq 65$ years, the mortality rate increased from 18.0 per 100,000 people in 1999 to 85.6 per 100,000 people in 2016 . The mortality rates among female adults aged $65-74,75-84$, and $\geq 85$ years increased from $2.3,14.3$, and 100.1 per 100,000 people in 1999 to $4.1,40.3$, and 376.6 per 100,000 people in 2016 , respectively.

Regarding the PoDs, the proportion of hospital deaths peaked around 2005 in both male and female adults, and declined consistently thereafter (Fig. 3). Similarly, the proportion of home deaths declined from $24.1 \%$ to $10.1 \%$ and from $30.9 \%$ to $10.7 \%$ for male and female adults, respectively (Fig. 4). In contrast, the proportion of nursing home deaths exhibited an upward trend over time, increasing from $13.0 \%$ to $28.4 \%$ in male adults and from $17.1 \%$ to $45.8 \%$ in female adults. Despite the observed decrease, hospital deaths still accounted for the highest proportion of PoDs relative to those in homes and nursing care facilities.

A trend analysis revealed that the APC of the mortality rate from dementia over the study period was $9.1 \%$ (8.2\% for male and $9.3 \%$ for female adults), indicating an increase over time (Table 1). Among both male and female adults, a comparison of age subgroups revealed a higher APC of mortality among older populations.

According to the trend analysis of $\mathrm{PoD}$, the proportion of hospital deaths decreased annually over the 18-year period, with an AAPC of $-1.0 \%$ (95\% CI, -1.3 to - 0.7) (Table 2). The proportion of hospital deaths tended to increase (1.7\%) until 2005, and then exhibited a downward trend $(-2.5 \%)$ thereafter. The proportion of people who spent the ends of their lives in their own homes consistently decreased, with an AAPC of $-5.8 \%(95 \%$ CI, -6.6 to -5.0$)$. Unlike in-hospital and home deaths, the proportion of deaths in a nursing home increased consistently among both sexes, with an AAPC of 5.6\% (95\% CI, 3.2 to 8.0).

\section{Discussion}

This is the first study to clarify trends in PoD among patients with dementia in Japan during 1999-2016. Notably, the mortality rates increased significantly among people with dementia aged $\geq 65$ years throughout the study period, and tended to increase in both sexes. Given the progressive nature of population ageing, this mortality rate is expected to increase in the future. Regarding the effect of age, the increase in mortality rate between 65-74 and 75-84 years of age was higher in men than in women. This might reflect the tendency of women to have a relatively longer life expectancy ${ }^{18}$. This increasing mortality rate might suggest that dementia has been recognised as an underlying cause of death in Japan. Improvements in death certificate notation in the future may lead to a further increase in reported deaths attributed to dementia, which may be underreported as an underlying cause of death. Further, the number of patients with dementia in Japan also increased during this period, thus the increase in deaths related to dementia might be attributable to this increase in the number of patients with dementia.

The proportions of PoD among patients with dementia changed significantly over the study period, reflecting the ageing of Japanese society. Overall, the prevalence of hospital deaths remained high among patients with dementia, although this rate has decreased significantly since the early 2000s. The promotion of home care services by the Ministry of Health, Labour, and Welfare, along with revisions of the medical and nursing care fees since the $1980 \mathrm{~s}^{19}$, might have contributed to the decreasing trend in hospital deaths. Regardless of government endorsements, however, the rate of dementia-associated deaths at home decreased from $28.8 \%$ in 1999 to $10.5 \%$ in 2016, with an AAPC of 5.8\% over the study period. In December 2017, the Ministry of Health, Labour, and Welfare of Japan mailed a questionnaire survey regarding the preferred $\mathrm{PoD}$ to 6,000 randomly selected adults aged $\geq 20$ years nationwide. The participants were instructed to assume the following: "...your dementia progresses, you need help from a caregiver for daily living, and you are considerably debilitated." According to the results of the survey, only $3.4 \%$ of Japanese citizens wish to die of advanced dementia in a hospital, whereas $63.5 \%$ selected a nursing care facility and $32.5 \%$ preferred their own home ${ }^{20}$. Among people who wished to die in places 

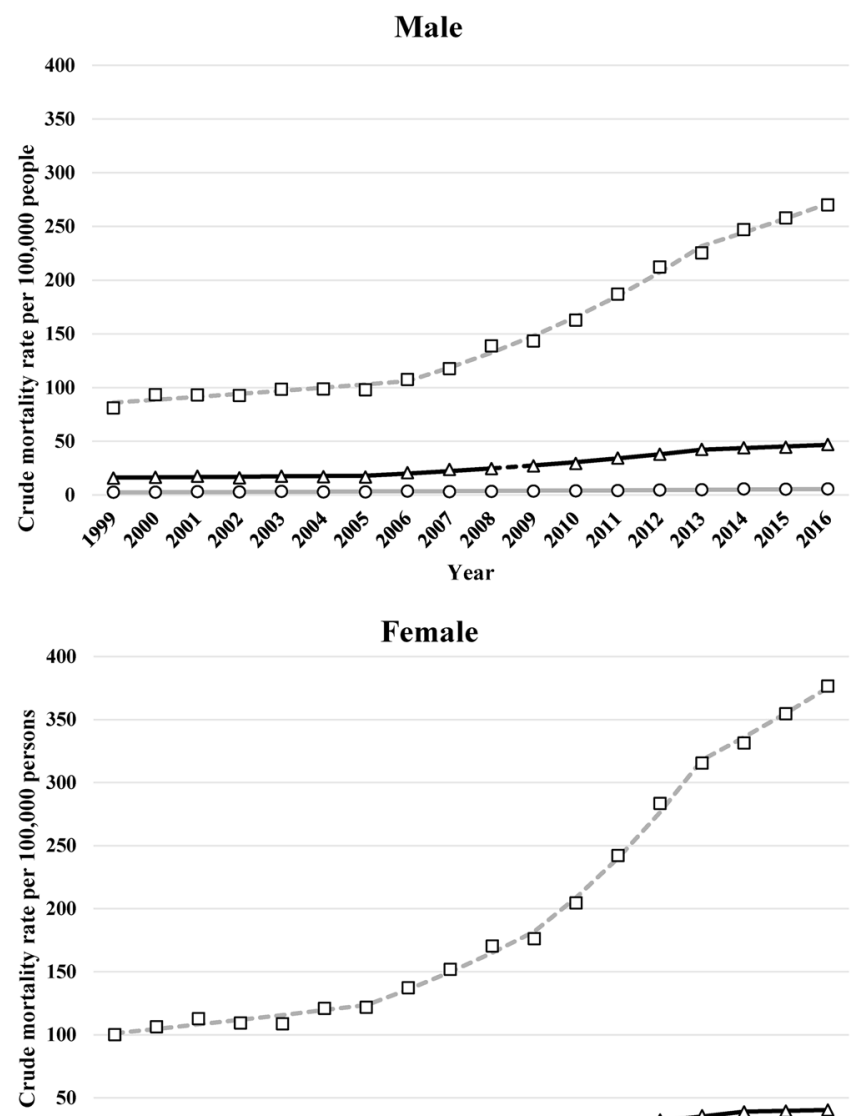

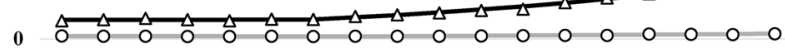

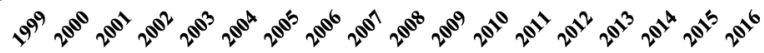

Year

$-65-74$ years, trend $\longrightarrow 75-84$ years, trend $\quad----\geq 85$ years, trend

○ 65-74 years, observed $\quad \Delta \quad 75-84$ years, observed $\quad \square \quad \geq 85$ years, observed

Figure 2. Trends in the crude mortality rates associated with dementia per 100,000 people aged $\geq 65$ years by age during 1999-2016.

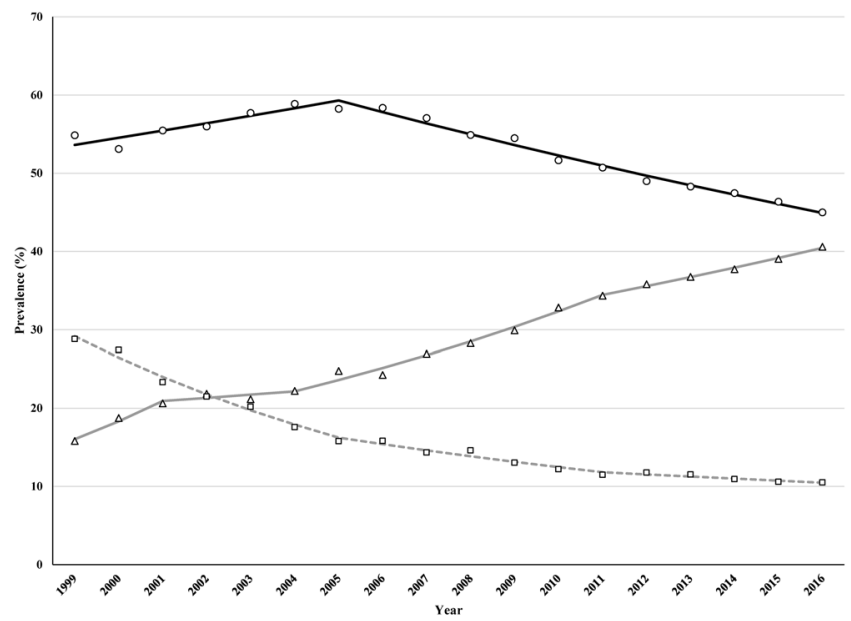

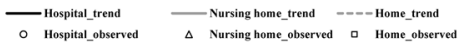

Figure 3. Trends in the prevalence rates of places of death among dementia patients aged $\geq 65$ years by age during 1999-2016. 
Male

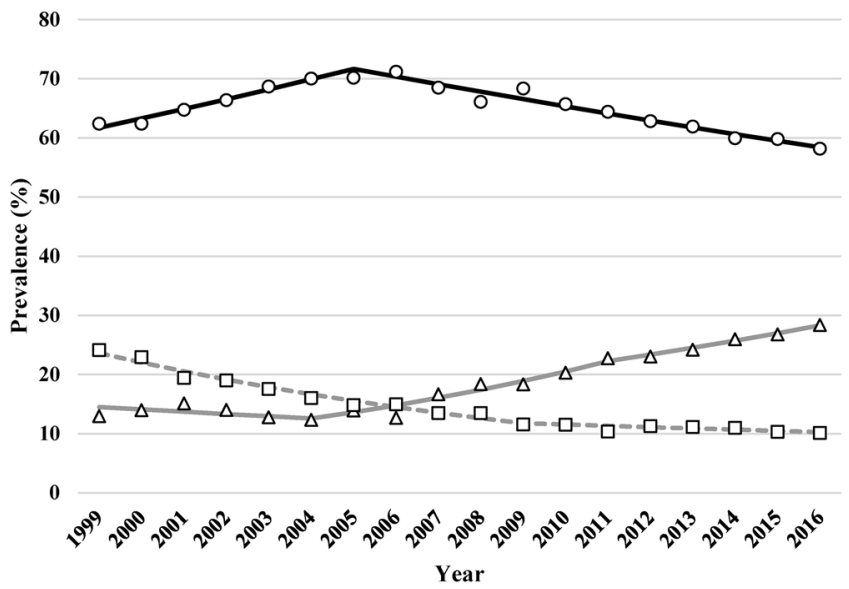

Female

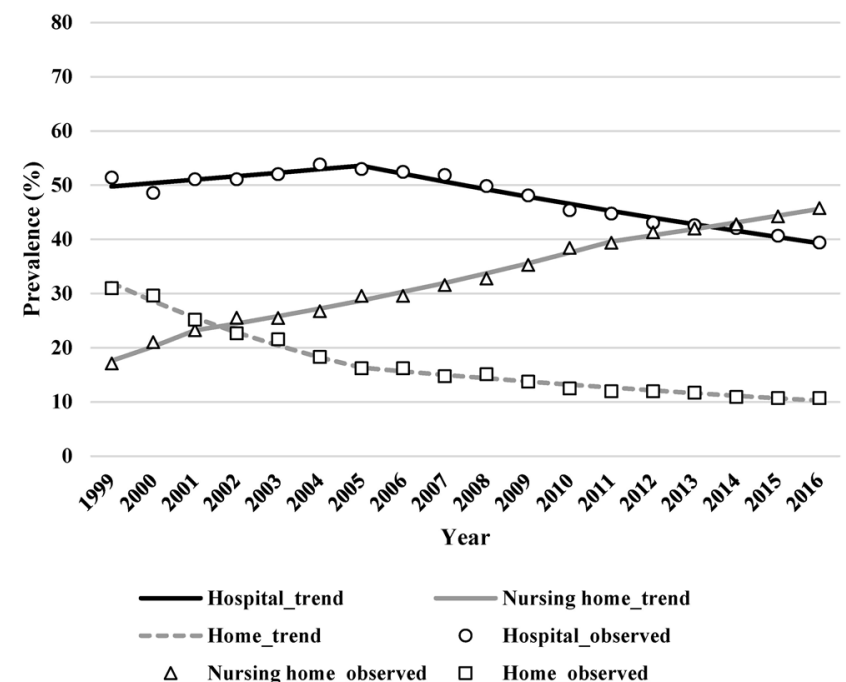

Figure 4. Trends in the prevalence rates of places of death among dementia patients aged $\geq 65$ years by sex during 1999-2016.

\begin{tabular}{|c|c|c|c|c|c|c|c|c|c|}
\hline \multirow{2}{*}{$\begin{array}{l}\text { Age group } \\
\text { (years) }\end{array}$} & \multicolumn{2}{|l|}{ Trend 1} & \multicolumn{2}{|l|}{ Trend 2} & \multicolumn{2}{|l|}{ Trend 3} & \multicolumn{2}{|l|}{ Trend 4} & \multirow{2}{*}{$\begin{array}{l}\text { Average APC } \\
{[95 \% \mathrm{CI}]}\end{array}$} \\
\hline & Years & APC (\%) & Years & APC (\%) & Years & APC (\%) & Years & APC (\%) & \\
\hline \multicolumn{10}{|l|}{ All } \\
\hline All ages & 1999-2005 & $4.4^{*}$ & 2005-2009 & 11.5 & 2009-2012 & $18.3^{*}$ & 2012-2016 & $7.5^{*}$ & $9.1 *[7.9$ to 10.4$]$ \\
\hline $65-74$ & 1999-2007 & 1.0 & $2007-2016$ & $7.4^{*}$ & & & & & $4.3 *[3.1$ to 5.5$]$ \\
\hline $75-84$ & 1999-2005 & 0.9 & 2005-2013 & $11.3^{*}$ & 2013-2016 & $4.1^{*}$ & 2012-2016 & $6.9 *$ & $6.3 *[5.1$ to 7.5$]$ \\
\hline$\geq 85$ & 1999-2005 & $3.2^{*}$ & 2005-2009 & $9.6^{*}$ & $2009-2012$ & $16.2^{*}$ & & & $7.8 *[6.7$ to 8.9$]$ \\
\hline \multicolumn{10}{|l|}{ Male } \\
\hline All ages & 1999-2005 & $2.9^{*}$ & $2005-2013$ & $13.1^{*}$ & $2013-2016$ & $6.2 *$ & & & $8.2 *[7.0$ to 9.3$]$ \\
\hline $65-74$ & 1999-2016 & $5.0^{*}$ & & & & & & & $5.0 *[4.2$ to 5.9$]$ \\
\hline $75-84$ & $1999-2005$ & 1.8 & $2005-2013$ & $11.3^{*}$ & $2013-2016$ & 3.4 & & & $6.5^{*}[5.4$ to 7.6$]$ \\
\hline$\geq 85$ & 1999-2006 & $3.0^{*}$ & $2006-2013$ & $11.8^{*}$ & $2013-2016$ & $5.4^{*}$ & & & $7.0 *[6.0$ to 8.0$]$ \\
\hline \multicolumn{10}{|l|}{ Female } \\
\hline All ages & 1999-2003 & 2.4 & 2003-2009 & $10.2^{*}$ & 2009-2012 & $19.7^{*}$ & 2012-2016 & $7.8^{*}$ & $9.3^{*}$ [7.9 to 10.8$]$ \\
\hline $65-74$ & 1999-2007 & -0.9 & $2007-2016$ & $8.2 *$ & & & & & $3.8^{*}[2.1$ to 5.5$]$ \\
\hline $75-84$ & 1999-2005 & 0.3 & $2005-2014$ & $10.9^{*}$ & $2014-2016$ & 1.6 & 2013-2016 & $5.7^{*}$ & $6.0^{*}[4.4$ to 7.6$]$ \\
\hline$\geq 85$ & 1999-2005 & $3.4^{*}$ & 2005-2009 & $10.1^{*}$ & $2009-2013$ & $15.0 *$ & & & $8.0 *[6.9$ to 9.2$]$ \\
\hline
\end{tabular}

Table 1. Trends in the crude death rates of patients with dementia by sex, 1999-2016. *Significantly different from zero $(\mathrm{p}<0.05)$. Abbreviations: APC, annual percentage change; CI, confidence interval. 


\begin{tabular}{|c|c|c|c|c|c|c|c|c|c|c|}
\hline \multirow[b]{2}{*}{ Facility } & \multicolumn{2}{|l|}{ Trend 1} & \multicolumn{2}{|l|}{ Trend 2} & \multicolumn{2}{|l|}{ Trend 3} & \multicolumn{2}{|l|}{ Trend 4} & \multirow{2}{*}{\multicolumn{2}{|c|}{ Average APC [95\% CI] }} \\
\hline & Years & APC [\%] & Years & APC [\%] & Years & APC [\%] & Years & APC [\%] & & \\
\hline \multicolumn{11}{|l|}{ All } \\
\hline Hospital & 1999-2005 & $1.7^{*}$ & 2005-2016 & -2.5 & & & & & $-1.0^{*}$ & {$[-1.3$ to -0.7$]$} \\
\hline Nursing Home & 1999-2001 & 14.2 & 2001-2004 & 1.9 & $2004-2011$ & $6.5^{*}$ & 2011-2016 & $3.3^{*}$ & $5.6^{*}$ & [3.2 to 8.0 ] \\
\hline Home & 1999-2005 & $-9.3^{*}$ & $2005-2011$ & -5.2 & 2011-2016 & $-2.4^{*}$ & & & $-5.8^{*}$ & [ -6.6 to -5.0$]$ \\
\hline \multicolumn{11}{|l|}{ Male } \\
\hline Hospital & 1999-2005 & $2.5^{*}$ & 2005-2016 & $-1.8^{*}$ & & & & & -0.3 & [ -0.7 to 0.0$]$ \\
\hline Nursing Home & 1999-2004 & -2.8 & 2004-2011 & $8.5^{*}$ & 2011-2016 & $4.9^{*}$ & & & $4.0^{*}$ & [2.0 to 6.1$]$ \\
\hline Home & 1999-2009 & $-6.7^{*}$ & $2009-2016$ & $-1.9^{*}$ & & & & & $-4.8^{*}$ & [ -5.5 to -4.0$]$ \\
\hline \multicolumn{11}{|l|}{ Female } \\
\hline Hospital & 1999-2005 & $1.2^{*}$ & 2005-2016 & $-2.8^{*}$ & & & & & $-1.4^{*}$ & [ -1.8 to -0.9$]$ \\
\hline Nursing Home & 1999-2001 & 14.7 & 2001-2011 & $5.5^{*}$ & 2011-2016 & $2.9^{*}$ & & & $5.8^{*}$ & [4.1 to 7.4 ] \\
\hline Home & 1999-2005 & $-10.6^{*}$ & $2005-2016$ & $-4.1^{*}$ & & & & & $-6.5^{*}$ & {$[-7.2$ to -5.7$]$} \\
\hline
\end{tabular}

Table 2. Trends in the prevalence of places of death of patients with dementia by sex, 1999-2016. *Significantly different from zero $(p<0.05)$. Abbreviations: APC, annual percentage change; $\mathrm{CI}$, confidence interval.

other than their own homes, $76 \%$ reported not wanting to burden their family members who cared for them. The results of this study suggest a potential disparity between the hope for a particular PoD and the actual PoD. However, the long-term trends indicate a decreasing pattern in the prevalence of hospital deaths and a corresponding increase in the prevalence of nursing homes as a PoD. This suggests a narrowing gap between the ideal and reality. As the prevalence and number of dementia-associated deaths in nursing homes increases over time, readjustments to the quantity and quality of care provided in such facilities should become an important public health issue. Hospitals may provide treatment or cure for the patient's disease and thus increase the lifespan, but may not necessarily offer care with comfort and compassion. Thus, improvements in nursing home care may be part of a major public health policy to prevent older people from dying in hospitals and improve the quality of end-of-life care in Japan. Based on this current situation, a future public health policy for patients with dementia requires serious consideration.

According to some previous studies on PoDs among patients with dementia, the prevalence of nursing homes was highest in the Netherlands at $92.3 \%(2003)^{12}$, followed by the United States at $66.9 \%(2001)^{13}$, Belgium at $65.9 \%(2003)^{12}$, the United Kingdom at 55.3\% (2001-2010) $)^{11}$, and Finland at 20.5\% (2013) ${ }^{10}$. In Japan, the prevalence of nursing homes as the choice for PoD was $30.9 \%$ in 2016 . As more than $60 \%$ of Japanese individuals report a preference to die in nursing homes ${ }^{20}$, it may be necessary to compensate for a shortage in nursing homes for people with dementia and their families. The rate of death at home was highest in Belgium at $16.4 \%$ $(2003)^{12}$, followed by $12.7 \%$ in the United States $(2001)^{13}, 8.1 \%$ (2013) in Finland ${ }^{10}, 4.8 \%(2001-2010)$ in the United Kingdom ${ }^{11}$, and $4.7 \%$ in the Netherlands $(2003)^{12}$. In Japan, the proportion of home deaths was $10.5 \%$ in 2016, which was consistent with previous reports from other countries. However, this rate has exhibited a downward trend and may decrease further in the future. Although these previous findings could not be compared directly because differences in the study periods and national health care systems, all suggested that people with dementia infrequently die at home. Rather, the frequency of deaths in nursing homes is increasing in many countries. However, as in-hospital deaths have decreased in Japan due to policy changes, the proportions of PoDs among patients with dementia in each of the different countries may also change in response to changing health care systems and policies. These policies should be developed and executed using limited financial resources to meet the desires of people in the respective societies.

According to a recent survey by the Economist ${ }^{19}$, Japan ranks $14^{\text {th }}$ among 80 countries worldwide for the quality of palliative care, despite its nature as an ageing society. Although a public long-term care insurance programme was established in 2000, we believe that more institutional support is required to promote end-of-life care. Moreover, advanced care planning that aims to respect an individual's wishes should be introduced to emphasise the importance of an informed decision-making process. This study, therefore, underscores the need to consider a multidisciplinary approach to achieving patient-centred end-of-life care for dying people with dementia. This approach should be based on a deep understanding of the PoDs of patients with dementia. We should also consider improving the quality of end-of-life care to fulfil the wishes of patients not only in nursing homes.

The strengths of this study include the availability of the national death certificate database and that it is the first investigation on the long-term trends in dementia-associated mortality and PoD in Japan, one of the world's most aged societies. Moreover, the application of the Joinpoint trend analysis to this type of research represents a very new approach which has only been reported in recent related studies ${ }^{14,21}$. However, the present study also has the following limitations. First, the underreporting of dementia as an underlying cause of death might have influenced the results. Second, although ICD-10 codes were utilised in this study, the validity of these data were uncertain because no clinical information on the direct association of dementia and death was available. Third, the results of the study might have been affected by long-term changes in physicians' perceptions of dementia as a cause of death. Fourth, the PoD proportion is a relative index, as the sum of the proportions is $100 \%$. Therefore, we provided the numbers of dementia-related deaths in each PoD in the Supplementary Table S2. Despite these limitations, this nationwide study involving an 18-year period has prominent implications for a 
deep understanding of the PoDs of patients with dementia and may lead to better health policy decisions for people living with dementia.

In conclusion, the dementia-associated mortality rate has increased in Japan, and the proportions of PoD have shifted between 1999 and 2016. In the near future, the majority of Japanese individuals with an underlying cause of death attributable to dementia might receive their end-of-life care in nursing homes rather than in hospitals. Therefore, the availability of nursing homes and quality of end-of-life care should be discussed among patients, families, health and nursing care providers, and policymakers to preserve the dignity of ageing individuals with dementia.

\section{Data availability}

Data in the study is available at: https://www.e-stat.go.jp/en/stat-search/files?page $=1 \&$ toukei $=00450011 \&$ tstat $=$ 000001028897.

Received: 25 June 2019; Accepted: 11 December 2019;

Published online: 27 December 2019

\section{References}

1. Mitchell, S. L. et al. The clinical course of advanced dementia. N. Eng. J. Med. 361, 1529-1538 (2009).

2. United Nations Department of Economic and Social Affairs. World Population Ageing 2017. New York (2017).

3. Organisation for Economic Co-operation and Development. OECD Factbook 2015/2016 - Economic, Environmental and Social Statistics (2016).

4. World Health Organization. Dementia: a public health priority. Dementia 112 (2012)

5. Ministry of Health, Labour, and Welfare. Patient survey. https://www.mhlw.go.jp/english/database/db-hss/ps.html (Accessed September 20th, 2019).

6. Mitchell, S. L. Advanced dementia. N. Eng. J. Med. 373, 1275-1277 (2015)

7. Sachs, G. A., Shega, J. W. \& Cox-Hayley, D. Barriers to excellent end-of-life care for patients with dementia. J. Gen. Intern. Med. 19, 1057-1063 (2004).

8. Teno, J. M. et al. Family perspectives on end-of-life care at the last place of care. JAMA. 291, 88-93 (2004).

9. Matsuda, S. \& Yamamoto, M. Long-term care insurance and integrated care for the aged in Japan. Int. J. Integr. Care. 1, e28 (2001).

10. Masuchi, Y., Jylhä, M., Raitanen, J. \& Aaltonen, M. Changes in place of death among people with dementia in Finland between 1998 and 2013: A register study. Alzheimers Dement (Amst). 10, 86-93 (2018).

11. Sleeman, K. E. et al. Reversal of English trend towards hospital death in dementia: a population-based study of place of death and associated individual and regional factors, 2001-2010. BMC Neurol. 14, 59 (2014).

12. Houttekier, D. et al. Place of death of older persons with dementia. A study in five European countries. J. Am. Geriatr. Soc. 58, 751-756 (2010).

13. Mitchell, S. L., Teno, J. M., Miller, S. C. \& Mor, V. A national study of the location of death for older persons with dementia. J. Am. Geriatr. Soc. 53, 299-305 (2005).

14. Niu, H., Alvarez-Alvarez, I., Guillen-Grima, F., Al-Rahamneh, M. J. \& Aguinaga-Ontoso, I. Trends of mortality from Alzheimer's disease in the European Union, 1994-2013. Euro. J. Neurol. 24, 858-866 (2017).

15. Ministry of Health, Labour and Welfare. Vital Statistics of Japan. https://www.e-stat.go.jp/en/stat-search/ files?page $=1 \&$ toukei $=00450011 \&$ tstat $=000001028897$ (Accessed October $\left.1^{\text {st }}, 2018\right)$.

16. World Health Organization. ICD-10: International Statistical Classification of Diseases and Related Health Problems: Tenth Revision, 2nd Ed. Geneva: World Health Organization (2004).

17. Kim, H. J., Fay, M. P., Feuer, E. J. \& Midthune, D. N. Permutation tests for joinpoint regression with applications to cancer rates. Stat. Med. 19, 335-351 (2000).

18. Hebert, L. E., Scherr, P. A., McCann, J. J., Beckett, L. A. \& Evans, D. A. Is the risk of developing Alzheimer's disease greater for women than for men? Am. J. Epidemiol. 153, 132-136 (2001).

19. Economist Intelligence Unit. The 2015 Quality of Death Index Ranking Palliative Care across the World (2015).

20. Ministry of Health, Labour, and Welfare. The survey of public attitude towards medical care in the end of life. https://www.mhlw.go.jp/ toukei/list/saisyuiryo.html (Accessed October 30th 2018).

21. Kalseth, J. \& Theisen, O. M. Trends in place of death: The role of demographic and epidemiological shifts in end-of-life care policy. Palliat. Med. 31, 964-974 (2017).

\section{Acknowledgements}

We would like to thank Editage (www.editage.jp) for English language editing. This publication was supported by Japan Society for the Promotion of Science KAKENHI (19K10533) (Tokyo, Japan).

\section{Author contributions}

T.K. conceived the study concepts. T.K. and M.S. performed statistical analyses. T.K., H.H., A.O. and T.F. provided technical support. T.K., M.S., H.H., Y.Z. and K.H. contributed to the interpretation of data and assisted in the preparation of the manuscript. T.K. and M.S. drafted the initial manuscript. H.H., Y.Z., T.F., A.O., Y.T., N.M., K.S., Y.K., T.S., S.H. and M.R.K. conducted a critical revision of the manuscript. All authors participated in revising the manuscript and approved the final version to be published.

\section{Competing interests}

The authors declare no competing interests.

\section{Additional information}

Supplementary information is available for this paper at https://doi.org/10.1038/s41598-019-56388-w.

Correspondence and requests for materials should be addressed to T.K.

Reprints and permissions information is available at www.nature.com/reprints.

Publisher's note Springer Nature remains neutral with regard to jurisdictional claims in published maps and institutional affiliations. 
(c) (i) Open Access This article is licensed under a Creative Commons Attribution 4.0 International License, which permits use, sharing, adaptation, distribution and reproduction in any medium or format, as long as you give appropriate credit to the original author(s) and the source, provide a link to the Creative Commons license, and indicate if changes were made. The images or other third party material in this article are included in the article's Creative Commons license, unless indicated otherwise in a credit line to the material. If material is not included in the article's Creative Commons license and your intended use is not permitted by statutory regulation or exceeds the permitted use, you will need to obtain permission directly from the copyright holder. To view a copy of this license, visit http://creativecommons.org/licenses/by/4.0/.

(C) The Author(s) 2019 